\title{
Intrasexual Competition and Eating Restriction in Heterosexual and Homosexual Individuals
}

\author{
Norman P. Li, \\ University of Texas at Austin, Singapore Management University
}

April R. Smith,

Florida State University

Vladas Griskevicius,

University of Minnesota

Margaret J. Cason, and

University of Texas at Austin

\section{Angela Bryan \\ University of New Mexico}

\begin{abstract}
Restrictive eating attitudes and behaviors have been hypothesized to be related to processes of intrasexual competition. According to this perspective, within-sex competition for status serves the adaptive purpose of attracting mates. As such, status competition salience may lead to concerns of mating desirability. For heterosexual women and gay men, such concerns revolve around appearing youthful and thus, thinner. Following this logic, we examined how exposure to high-status and competitive (but not thin or highly attractive) same-sex individuals would influence body image and eating attitudes in heterosexual and in gay/lesbian individuals. Results indicated that for heterosexuals, intrasexual competition cues led to greater body image dissatisfaction and more restrictive eating attitudes for women, but not for men. In contrast, for homosexual individuals, intrasexual competition cues led to worse body image and eating attitudes for gay men, but not for lesbian women. These findings support the idea that the ultimate explanation for eating disorders is related to intrasexual competition.
\end{abstract}

\section{Keywords}

intrasexual competition; sex differences; sexual orientation; eating disorders; body image

\footnotetext{
(c) 2010 Elsevier Inc. All rights reserved.

Address correspondence to Norman P. Li, Singapore Management University, School of Social Sciences, 90 Stamford Road, Level 4, Singapore 178903; normanli@smu.edu.sg.

Publisher's Disclaimer: This is a PDF file of an unedited manuscript that has been accepted for publication. As a service to our customers we are providing this early version of the manuscript. The manuscript will undergo copyediting, typesetting, and review of the resulting proof before it is published in its final citable form. Please note that during the production process errors may be discovered which could affect the content, and all legal disclaimers that apply to the journal pertain.
} 


\subsection{Intrasexual Competition and Eating Restriction in Heterosexual and Homosexual Individuals}

Approximately 11 million Americans suffer from an eating disorder such as anorexia nervosa or bulimia nervosa (National Eating Disorders Association, 2006). Anorexia nervosa is the deadliest psychological illness, resulting in a 10\% death rate (e.g., Birmingham, Su, Hlynsky, Goldner, \& Goa, 2005). Many more people simply want to be thin and feel averse toward eating. Indeed, $80 \%$ of women report being dissatisfied with their body shape (Smolak, 1996). Such dissatisfaction tends to be firmly established in adolescence (e.g., Vohs, Heatherton, \& Herrin, 2001), whereby half of teenage girls skip meals, vomit, or engage in other extreme weight control practices (Neumark-Sztainer, 2005). From an evolutionary perspective, self-destructive eating behaviors seem paradoxical. Voluntarily starving or purging food would generally not have been favored by natural selection. Yet, the prevalence of eating disorders suggests that an adaptive mechanism might underlie this phenomenon.

We examined the idea that eating restriction in pursuit of thinness may be linked to intrasexual competition for status and, ultimately, for mates (Abed, 1998; Faer, Hendriks, Abed, \& Figueredo, 2005). Specifically, eating restriction may result from perpetual competition with same-sex individuals. Although the nature of such competition is adaptive, the underlying mechanisms may be excessively triggered by abundant competitive stimuli in the modern world.

\subsection{The Roots of Eating Restriction}

In their review of attitudes toward female body fat, Anderson, Crawford, Nadeau, \& Lindberg (1992) noted the cross-cultural variability in such attitudes. Thinness in females, as well as both major forms of eating pathologies (anorexia nervosa and bulimia nervosa), is more prevalent in western versus non-western (e.g., Makino, Tsuboi, \& Dennerstein, 2004) and industrialized versus non-industrialized nations (e.g., Choudry \& Mumford, 1992).

Accordingly, many researchers have attributed eating restriction and related issues to cultural norms for female thinness (e.g., Polivy, Garner, \& Garfinkel, 1986), made salient through media (e.g., Thompson, Heinberg, Altabe, \& Tantleff-Dunn, 1999). Indeed, viewing thin versus non-thin magazine models results in more negative mood, body dissatisfaction, and eating disorder symptoms among Western women (Hawkins, Richards, Granley, \& Stein, 2004). Similarly, viewing TV commercials (Heinberg \& Thompson, 1995) or music videos (Tiggemann \& Slater, 2004) highlighting actresses' appearances negatively impacts women's body image satisfaction. Such studies, however, have rarely considered where the cultural preferences originated and why media images are so readily processed (Anderson et al., 1992).

Searching for more ultimate explanations, some researchers have proposed evolutionary hypotheses for restrictive eating and the desire for thinness (see Anderson et al., 1992). One promising hypothesis concerns adaptive reproductive suppression. That is, when female mammals face ecological conditions unfavorable for rearing offspring, they may temporarily halt fertility through the restriction of eating, which causes body fat to drop below the minimal level needed for ovulation (Surbey, 1987; Voland \& Voland, 1989; Wasser \& Barash, 1983). For adolescent girls and women, whether or not ovulation occurs may be sensitive to small changes in weight if their body fat composition is near the critical level (Frisch, 1990). As such, in environments where social support is variable, it may be adaptive to generally be slender and to be especially averse to weight gain and eating when social support for childrearing is lacking (Anderson et al., 1992). 
Support for this hypothesis has been found through studies linking social conditions and relevant attitudes. For example, perceived lack of social support (Juda, Campbell, \& Crawford, 2004) and local norms valuing women in the workforce (Anderson et al., 1992), are associated with dieting and negative attitudes toward female body fat. Furthermore, Salmon, Crawford, Dane, \& Zuberbier (2008) found that merely imagining oneself in various stressful situations can induce greater body dissatisfaction and restrictive eating attitudes in women. Although it is a plausible ultimate explanation, reproductive suppression tends to be limited to explaining symptoms of anorexia nervosa and does not address the development of similarly negative eating attitudes and behaviors in men. Indeed, although eating disorders are typically associated with women, up to $15 \%$ of individuals with eating disorders are men (Carlat and Camargo, 1991).

A more general ultimate explanation that may also apply to eating restriction, as well as a wider range of disordered eating behaviors, is that it is rooted in adaptive mechanisms for intrasexual competition. Across species, a primary function of competing with members of one's own sex is to attract viable mates (Darwin, 1871). Indeed, for human males and females, tactics for competing intrasexually for status are essentially mate attraction tactics (Buss, 1988; Walters $\&$ Crawford, 1994). Because men value cues of youth and fertility in their mates (Symons, 1979), women compete intrasexually on physical attractiveness for status. The dimensions that are specifically valued may depend on local social input. In Western societies, people tend to gain weight with age as metabolic rates and physical activity decrease (e.g., Keel, Baxter, Heatherton, \& Joiner, 2007) and female thinness tends to be equated with youth and status (Sobal \& Stunkard, 1989). Thus, abundant media images of thin females may be over-activating an otherwise adaptive mechanism to compete against one's actual peers on appearance.

To date, many studies have demonstrated the negative effects of media-portrayed thinness and, more generally, physical attractiveness, on body image and eating attitudes. Most of these studies posit that the desire for thinness is driven by modeling and social norms, whereby exposure to glamorous images of attractive, thin women leads young women to imitate such models. However, an intrasexual competition model suggests that a wider range of stimuli should be capable of triggering a desire for thinness and thus, restrictive eating. That is, if intrasexual competition for status ultimately serves the adaptive purpose of attracting mates, then a general activation of intrasexual competition motives - even when cues related to appearance, attraction, or mating are absent - may be enough to trigger mating desirability concerns. For women, such concerns are oriented around appearing more youthful and fertile (i.e., nubile). In contrast, women tend not to be romantically interested in men who are very young (Kenrick \& Keefe, 1992). Thus, the triggering of mating desirability through intrasexual competition would be expected to bring about desires for thinness and eating restriction in women, but not men.

\subsection{Intrasexual Competition and Sexual Orientation}

Although eating restriction should be a female - but not male - response to intrasexual competition cues, the opposite may apply for homosexual individuals. Gay men, but not lesbian women, especially value physical attractiveness (Bailey et al., 1994) and youth (Kenrick, Keefe, Bryan, Barr, \& Brown, 1995) in their romantic partners. Compared with heterosexual men, gay men report greater body dissatisfaction (e.g., Beren, Hayden, \& Wilfley, 1996) and disordered eating tendencies (Herog et al., 1984; Yager, Kurtzman, Landsverk, \& Weismeier, 1988). In contrast, lesbian women score lower than or equal to heterosexual women on such measures (e.g., Striegel-Moore, Tucker, \& Hsu, 1990). If the intrasexual competition perspective is correct, then gay men - but not lesbian women - should also respond to intrasexual competition cues by competing on thinness to increase their status as desirable mates. 


\subsection{The Current Research}

We sought to elucidate the evolutionary underpinnings of eating restriction by examining whether adaptive processes of intrasexual status competition might underlie the prevalence of eating restriction in pursuit of thinness. In Study 1, we experimentally manipulated intrasexual status competition by having participants view same-sex individuals who were described either as competitive and having high status, or as noncompetitive and having relatively low status. Considering the ultimate function of intrasexual competition, we predicted that cues to intrasexual competition among women - but not among men - would be manifest in concerns of thinness and restrictive eating attitudes.

In Study 2, we more extensively tested the intrasexual competition hypothesis, extending it beyond the reach of the reproductive suppression hypothesis. Specifically, we examined the effects of intrasexual competition cues on not only restrictive eating attitudes but also body image and expanded our participants to include a gay and lesbian sample,

\subsection{Study 1: Intrasexual Competition and Eating Attitudes}

We examined how priming people with intrasexual competition cues influences their attitudes toward eating. Competition cues consisted of photos and profiles of high-status, competitive same-sex individuals. Importantly, photos in the control and the competition conditions did not differ in attractiveness or body weight. Similar status-competition priming procedures have recently been used by others (e.g., Ermer, Cosmides, \& Tooby, 2008). Based on an intrasexualstatus-competition model, we predicted that competition cues would lead to more restrictive eating attitudes among women, but not among men.

\subsection{Method}

2.11 Participants-Participants were 458 introductory psychology students at University of Texas at Austin: 220 women, aged 16 to $23(M=18.42 \pm 0.88)$, and 238 men, aged 17 to 34 $(M=19.02 \pm 1.94)$.

2.12 Design and Materials-Between-subject independent variables were participant sex (male, female) and target competitiveness (competitive, noncompetitive). Each target profile consisted of a color head-shot photo and a self-description. We used 20 female and 20 male photos of normal-weight college students, pre-rated on physical attractiveness by 74 undergraduates $(1=$ extremely unattractive, $9=$ extremely attractive). Photos were of average attractiveness for female $(M=5.21 \pm 2.03)$ and male faces $(M=5.05 \pm 2.20)$.

To prime intrasexual competition, each profile included a one-paragraph self-description, supposedly written by a fellow student, conveying competitiveness and status through interests, academic and community involvement, and employment. In total, we used 10 profiles conveying competitiveness/high-status in different interest areas, and 10 noncompetitive/lowstatus profiles matched on interest area with the competitive profiles. Whereas competitive targets discussed playing to win, taking on leadership positions, and aiming to succeed, targets with corresponding noncompetitive profiles discussed playing for fun, joining (but not leading) organizations, and being content to get by. Profiles were written to be gender neutral so that the same ones could be used for both sexes. Importantly, no reference was made to physical appearance, dieting, eating, or mating. The profiles were pre-rated for competitiveness on a 9point scale $(1=$ extremely noncompetitive, $9=$ extremely competitive $)$. The 10 competitive/ high status profiles $(M=7.44 \pm 0.85)$ and 10 corresponding noncompetitive/low-status profiles $(M=3.73 \pm 1.05)$ differed in perceived competitiveness, $t_{18}=2.70, p<.001, r=.54$.

To measure eating attitudes, we used the 26-item Eating Attitudes Test (EAT-26; Garner \& Garfinkel, 1979). The EAT measures behaviors, thoughts, and feelings related to disordered 
eating, including restriction (e.g., "I avoid eating when hungry"), purging (e.g., "I have the impulse to vomit after meals") and a strong desire for thinness (e.g., "I am preoccupied with a desire to be thinner"). It has been validated in both clinical and non-clinical populations (see Garner, Olmstead, Bohr, \& Garfinkel, 1982), and used as a dependent variable in experimental studies (e.g., Cameron \& Ferraro, 2004). Higher EAT scores are associated with more restrictive and eating-averse attitudes. Baseline averages for the EAT-26 in a non-clinical sample of men and women taken at two points six months apart were $4.0(95 \% \mathrm{CI}=3.4-4.6)$ and $4.2(95 \% \mathrm{CI}=3.5-4.8)$ (Eagles, McLeod, Mercer, \& Watson, 2000).

2.13 Procedure-Participants were told they were engaging in two studies and that for the first one, they would be evaluating student profiles for an alleged campus dating service. Next, 10 competitive or non-competitive same-sex targets were presented sequentially in random order on a computer screen. Each target's profile was shown for 45 seconds. Participants were then prompted to rate the target on competitiveness using 9-point scales. Following each rating, the next stimulus appeared. After completing this part of the experiment, participants were told that the next study involved surveying a variety of interpersonal attitudes. Participants then filled out a survey packet, which included the EAT-26; two competitiveness items: "I feel the need to compete with others" and "Competition is a part of life"; and one appearance satisfaction item: "I am satisfied with my physical appearance" ( 1 = strongly disagree, $9=$ strongly agree). When asked about the purpose of the study, participants did not indicate suspicion that the first study was a manipulation for the second study.

\subsection{Results}

2.21 Manipulation check-Participants rated themselves as more competitive (average of the two competitiveness items $)$ in the competitive $(M=7.26, S D=1.13)$ versus noncompetitive condition $(M=6.85 \pm 1.39), F_{1,441}=11.80 p<.001, r=.16$.

2.22 Participant eating attitudes-An ANOVA using the EAT composite as the dependent variable yielded a participant sex $\times$ competitiveness interaction, $F_{1,441}=5.13, p=$. $024, r=.11$. As shown in Fig. 1, men who viewed competitive male profiles subsequently reported similar EAT scores $(M=5.38 \pm 4.16)$ to men who viewed noncompetitive male profiles $(M=5.49 \pm 4.95), F_{1,442}=0.01$. In contrast, women who viewed competitive female profiles subsequently reported significantly higher (more restrictive/averse) EAT scores ( $M=$ $8.22 \pm 7.32)$ than women who viewed noncompetitive profiles $(M=6.01 \pm 4.69), F_{1,442}=$ $8.94, p=.003, r=.14$.

\subsection{Discussion}

Exposure to competitive/high-status versus non-competitive/low-status same-sex others led to changes in women's - but not men's - eating attitudes. Mere exposure to competitive/highstatus women led female participants to have more restrictive and aversive eating attitudes and greater desire for thinness. Importantly, the high- vs. low-status women in the manipulation profiles did not differ in their weight or physical attractiveness. This pattern of results is consistent with women's desire to be thin reflecting an intrasexual competition processes.

\subsection{Study 2: Heterosexual and Homosexual Individuals}

Next, we expanded our investigation in two ways. First, we included body image, a construct closely related to eating attitudes (e.g., Hawkins et al., 2004), as a dependent variable. If intrasexual competition cues are inducing more restrictive and aversive eating attitudes through concerns over mating desirability, then the cues should also lead to more negative body image in heterosexual women. Second, we examined how intrasexual competition cues would influence eating attitudes in homosexual individuals. Whereas other evolutionary hypotheses 
such as reproductive suppression do not address disordered eating in men, an intrasexual competition perspective does. That is, both sexes engage in intrasexual competition for purposes of mate attraction (e.g., Buss, 1988). Because gay men's romantic partners also desire youth (Bailey et al., 1994; Kenrick et al., 1995), this perspective predicts that gay men would react similarly to competitive stimuli as heterosexual women by feeling the need to be thinner.

\subsection{Method}

3.11 Participants-There were 383 participants from University of Texas at Austin: 181 women, aged 16 to $53(M=20.83 \pm 3.6)$, and $202 \mathrm{men}$, aged 16 to $60(M=21.48 \pm 3.9)$. Some participants (120 women, 95 men) were introductory psychology students. Homosexual students (61 women, $107 \mathrm{men}$ ) were recruited via school newspaper advertisements and flyers given to campus gay and lesbian organizations offering $\$ 15$ for participation.

3.12 Design and Materials-We used Study 1's experimental design and stimuli and added the 34-item Body Shape Questionnaire (BSQ; Cooper, Taylor, Cooper, \& Fairburn, 1987) to assess participants' negative thoughts and feelings about their bodies. The BSQ has good testretest reliability and concurrent validity with other body image measures (Rosen, Jones,

Ramirez, \& Waxman, 1996). Typically, participants answer how they have been feeling over the past four weeks. For our study time was not specified, thus giving the questionnaire a more immediate and momentary quality. For sexual orientation, we used the Kinsey Scale of Sexual Orientation (Kinsey, Pomeroy, Martin, \& Gebhard, 1953). Study 1's procedure was followed.

\subsection{Results}

3.21 Effects of intrasexual competition cues on eating attitudes-A General Linear Model (GLM) using the EAT composite as the dependent variable and Kinsey score $(0=$ exclusively heterosexual, $6=$ exclusively homosexual) as a covariate produced a 3 -way sex $\times$ sexual orientation $\times$ competitiveness interaction, $F_{3,373}=4.36, p=.005, r=.11$. To examine the interaction, we dichotomized the sexual orientation scores. For both sexes, a global mode of individuals scored exactly 0 on the Kinsey scale, with frequencies dropping off until 1. Thus, we classified those individuals scoring up to $1(M=0.12 \pm 0.24)$ as heterosexual, and above $1(M=4.90 \pm 1.11)$ as homosexual (non-heterosexual). An ANOVA with the dichotomized variable produced a 3-way interaction with participant sex, competitiveness, and sexual orientation, $F_{1,373}=4.52, p=.034, r=.11$. As shown in Fig. 2 , heterosexual women reported higher EAT scores in the competitive $(M=11.77 \pm 12.33)$ versus noncompetitive condition $(M=6.16 \pm 4.96), F_{1,376}=13.45, p<.001, r=.19$. In contrast, heterosexual men's EAT scores stayed relatively low across both competitiveness conditions, $F=.28$. For homosexual individuals, the pattern reversed (Fig. 3). Gay men reported more restrictive eating attitudes in the competitive $(M=10.81 \pm 9.46)$ versus noncompetitive condition $(M=6.79 \pm$ 6.22 ), $F_{1,376}=5.31, p=.022, r=.12$, whereas lesbian women's eating attitudes were similar between competitiveness conditions, $F=.57$.

\subsection{Effects of intrasexual competition cues on body image concerns-To}

examine if body image concerns were affected by competitiveness activation, we ran a GLM with participants' BSQ scores as the dependent variable and Kinsey score as a covariate. There was a 3-way sex $\times$ sexual orientation $\times$ competitiveness interaction, $F_{3,373}=7.21, p=.008, r=$. 14. Simple effects tests using the dichotomized sexual orientation variable revealed patterns similar to those for eating attitudes. Heterosexual women indicated greater body image concerns in the competitive condition $(M=94.23 \pm 32.88)$ than in the noncompetitive condition $(M=82.75 \pm 23.72), F_{1,376}=4.50, p=.035, r=.11$. However, there was no competitiveness effect for heterosexual men, $F=.86$. Homosexual individuals showed the opposite pattern. Gay men reported more concerns in the competitive $(M=89.31 \pm 32.66)$ versus noncompetitive 
condition $(M=75.59 \pm 27.26), F_{1,376}=4.33, p=.038, r=.11$, whereas lesbian women did not differ in body image concerns between competitiveness conditions, $F=.10$.

\subsection{Discussion}

Exposure to intrasexual competition cues had a very different effect on eating attitudes and body image depending on individuals' sex and sexual orientation. Whereas heterosexual men showed no differences, heterosexual women reported more restrictive eating attitudes and body image concerns after exposure to competitive versus noncompetitive same-sex individuals. In contrast, gay men, but not lesbian women, reported more restrictive eating attitudes and less favorable body image. These findings support the intrasexual competition hypothesis for thinness-related eating restriction.

\subsection{General Discussion}

We examined the hypothesis that eating restriction in the pursuit of thinness may reflect underlying motives for intrasexual competition. In two studies, we measured how simple exposure to competitive versus noncompetitive same-sex individuals influenced men's and women's eating attitudes and body image in both a heterosexual and homosexual population.

As predicted, cues to intrasexual competition led heterosexual women and gay men to report worse body image and more restrictive eating attitudes. However, also consistent with our framework, intrasexual competition cues did not influence body image or eating attitudes for lesbian women or heterosexual men. These results experimentally support the hypothesis that body image dissatisfaction and eating restriction may be ultimately driven by intrasexual competition. Also, because homosexual men responded to intrasexual competition, our results extend beyond the scope of other adaptive hypotheses, such as reproduction suppression, which only address female eating restriction. Furthermore, the findings are consistent with a modularity view of sexual orientation, whereby preferences and mechanisms of homosexual individuals are not all the same as those of same-sex heterosexual individuals (Kenrick et al., 1995).

Although previous studies have emphasized the role of thin and physically attractive media images on disordered eating, our manipulations of intrasexual competition consisted of pictures of normal-weight, average-looking peers. Thus, our experimental findings suggest the range of stimuli that can trigger thinness-driven eating restriction may be broader than previously considered. As such, abundant stimuli in modern settings, processed by mechanisms for status competition, may underlie clinical eating disorders.

\subsection{Future Directions}

The current findings open up future research possibilities. For instance, although the reproductive suppression hypothesis does not address male body image and eating disorders, the current results for heterosexuals are nevertheless compatible with that view, which would hypothesize that environmental cues linked to stressful situations - including competition should trigger female eating restriction (Salmon et al., 2008). To differentiate between the two evolutionary explanations, future research should more carefully examine the extent to which restrictive eating and body image are induced by stress versus competitiveness cues.

Whereas previous research has tended to examine the effects of exposure to thin and physically attractive models on body image and eating attitudes, we looked at how targets' competitiveness affects these variables. In the future, it would be beneficial to combine both competitiveness and physical attributes into one study. Such research could include specific features such as the waist-to-hip ratio that are more directly linked to fertility (Singh, 1993). There may be an 
interactive effect such that competitiveness from thin or physically attractive individuals would cause especially high amounts of body image concerns and eating restriction.

Although women do not especially value youth in their partners, they do value other aspects of physical attractiveness, including upper body strength and muscularity (e.g., Dixson, Halliwell, East, Wignarajah, \& Anderson, 2003; Li \& Kenrick, 2006), and masculine facial features (e.g., Johnston, Hagel, Franklin, Fink, \& Grammer, 2001) - traits linked to male fitness (see Frederick \& Haselton, 2007). Thus, it would be interesting to examine if cues to intrasexual competition might induce men to lose excess weight, build muscle, or improve their fitness.

A particular within-person variable that may be interesting to investigate is a woman's ovulatory cycle. Recent studies have shown that women are more prone to enhancing physical appearance when they are ovulating than when not ovulating (Durante et al., 2008; Haselton, Mortezaie, Pillsworth, Bleske-Recheck, \& Frederick, 2007). To the extent that this is due to being more intrasexually competitive, we would expect women to be especially likely to indicate restrictive eating attitudes in response to cues of status competition around the time of ovulation.

\subsection{Conclusion}

Our experiments provide preliminary evidence that adaptive processes of intrasexual competition may underlie the phenomenon of eating restriction in pursuit of thinness. Because intrasexual status hierarchies tend to center around qualities that are desirable to mates, we have asserted that intrasexual competition cues should elicit desires to be especially thin for many individuals. In particular, heterosexual women and gay men have mates who highly value youthfulness, so these groups should be especially susceptible to real or imagined pressure for competition and status based on a youthful appearance.

To effectively treat a psychological disorder, it is helpful to first understand the normal functions of psychological mechanisms that underlie the undesirable condition (Nesse, 2005). In this regard, knowing that individuals normally compete intrasexually for status - for some, status based on physical attractiveness and thinness - and that competition motives can be activated by exposure to competitive people, can help us more effectively address problematic body image and eating attitudes. Although competition with peers is a part of life, steps can be taken to limit one's exposure to successful, high status people depicted in modern media, who may falsely trigger competition mechanisms. In general, the modern world is full of evolutionarily novel circumstances that, when processed by otherwise-adaptive mechanisms, may contribute to the development of various psychological maladies (e.g., Kanazawa, 2004; Nesse \& Williams, 1994). The treatment and prevention of these often-deadly problems will require clinicians to become more knowledgeable about evolutionary psychology.

\section{Acknowledgments}

This research was supported, in part, by a grant from the National Institute of Mental Health (NIMH) to April R. Smith (F31 MH083382).

\section{References}

Abed RT. The sexual competition hypothesis for eating disorders. British Journal of Medical Psychology 1998;71:525-547. [PubMed: 9875960]

Anderson JL, Crawford CB, Nadeau J, Lindberg T. Was the Duchess of Windsor right? A cross-cultural review of the socioecology of ideals of female body shape. Ethology \& Sociobiology 1992;13:197227.

Evol Hum Behav. Author manuscript; available in PMC 2011 September 1. 
Bailey JM, Gaulin S, Agyei Y, Gladue BA. Effects of gender and sexual orientation on evolutionary relevant aspects of human mating psychology. Journal of Personality and Social Psychology 1994;66:1081-1093. [PubMed: 8046578]

Birmingham CL, Su J, Hlynsky JA, Goldner EM, Gao M. The mortality rate from anorexia nervosa. International Journal of Eating Disorders 2005;38:143-146. [PubMed: 16134111]

Beren SE, Hayden HA, Wilfley DE, Grilo CM. The influence of sexual orientation on body dissatisfaction in adult men and women. International Journal of Eating Disorders 1996;20:135-141. [PubMed: 8863065]

Buss DM. The Evolution of Human Intrasexual Competition: Tactics of Mate Attraction. Journal of Personality \& Social Psychology 1988;54:616-628. [PubMed: 3367282]

Cameron EM, Ferraro FR. Body dissatisfaction in college women after brief exposure to magazine images. Perceptual and Motor Skills 2004;98:1093-1099. [PubMed: 15209326]

Carlat DJ, Camargo CA. Review of bulimia nervosa in males. American Journal of Psychiatry 1991;148:831-843. [PubMed: 2053621]

Choudry I, Mumford DB. A pilot study of eating disorders in Mirpur (Pakistan) using an Urdu version of the Eating Attitudes Test. International Journal of Eating Disorders 1992;11:243-251.

Cohen, MN. Health and the rise of civilization. New Haven: Yale University Press; 1989.

Cooper PJ, Taylor MJ, Cooper Z, Fairburn CG. The development and validation of the Body Shape Questionnaire. International Journal of Eating Disorders 1987;6:485-494.

Dixson AF, Halliwell G, East R, Wignarajah P, Anderson M. Masculine somatotype and hirsuteness as determinants of sexual attractiveness to women. Archives of Sexual Behavior 2003;32:29-39. [PubMed: 12597270]

Durante KM, Li NP, Haselton MG. Changes in women's choice of dress across the ovulatory cycle: Naturalistic and experimental evidence. Personality and Social Psychology Bulletin 2008;34:14511460. [PubMed: 18719219]

Eagles JM, McLeod IH, Mercer G, Watson F. Seasonality of eating pathology on the Eating Attitudes Test in a nonclinical population. International Journal of Eating Disorders 2000;27:335-340. [PubMed: 10694720]

Ermer E, Cosmides L, Tooby J. Relative status regulates risky decision making about resources in men: Evidence for the co-evolution of motivation and cognition. Evolution and Human Behavior 2008;29:106-118. [PubMed: 19255605]

Faer LM, Hendriks A, Abed RT, Figueredo AJ. The evolutionary psychology of eating disorders: Female competition for mates or for status? Psychology and Psychotherapy: Theory, Research and Practice 2005;78:397-417.

Frederick DA, Haselton MG. Why is male muscularity sexy? Tests of the fitness indicator hypothesis. Personality and Social Psychology Bulletin 2007;33:1167-1183. [PubMed: 17578932]

Frisch, RE. Body fat, menarche, fitness, and fertility. In: Frisch, RE., editor. Adipose Tissue and Reproduction. Basel, Switzerland: Karger; 1990. p. 1-26.

Garner DM, Garfinkel PE. The Eating Attitudes Test: An index of the symptoms of anorexia nervosa. Psychological Medicine 1979;9:273-279. [PubMed: 472072]

Garner DM, Olmstead MP, Bohr Y, Garfinkel PE. The Eating Attitudes Test: Psychometric features and clinical correlates. Psychological Medicine 1982;12:871-878. [PubMed: 6961471]

Gutierres SE, Kenrick DT, Partch JJ. Beauty, dominance, and the mating game: Contrast effects in selfassessment reflect gender differences in mate selection. Personality and Social Psychology Bulletin 1999;25:1126-1134.

Haselton MG, Mortezaie M, Pillsworth EG, Bleske-Recheck AE, Frederick DA. Ovulation and human female ornamentation: Near ovulation, women dress to impress. Hormones and Behavior 2007;51:40-45. [PubMed: 17045994]

Hawkins N, Richards PS, Granley HM, Stein D. The impact of exposure to the thin-ideal media image on women. Eating Disorders: Journal of Treatment and Prevention 2004;12:35-50.

Heinberg L, Thompson K. Body image and televised images of thinness and attractiveness: A controlled laboratory investigation. Journal of Social and Clinical Psychology 1995;14:325-338. 
Herzog DB, Norman DK, Gordan C, Pepose M. Sexual conflict and eating disorders in 27 males. American Journal of Psychiatry 1984;141:989-990. [PubMed: 6589965]

Johnston VS, Hagel R, Franklin M, Fink B, Grammer K. Male facial attractiveness. Evidence for hormone-mediated adaptive design. Evolution and Human Behavior 2001;22:251-267.

Juda M, Campbell L, Crawford C. Female dieting as a result of a lack of social support: An evolutionary approach. Evolution and Human Behavior 2004;25:200-208.

Kanazawa S. The Savanna Principle. Managerial and Decision Economics 2004;25:41-54.

Keel PK, Baxter M, Heatherton TF, Joiner TE. A 20-year longitudinal study of body weight, dieting, and eating disorder symptoms. Journal of Abnormal Psychology 2007;116:422-432. [PubMed: 17516772]

Kenrick DT, Keefe RC, Bryan A, Barr A, Brown S. Age preferences and mate choice among homosexuals and heterosexuals: A case for modular psychological mechanisms. Journal of Personality and Social Psychology 1995;69:1166-1172.

Kinsey, AC.; Pomeroy, WB.; Martin, CE.; Gebhard, PH. Sexual behavior in the human female. Oxford, England: Saunders; 1953.

Li NP, Kenrick DT. Sex similarities and differences in preferences for short-term mates: What, whether, and why. Journal of Personality and Social Psychology 2006;90:468-489. [PubMed: 16594832]

Makino, M.; Tsuboi, K.; Dennerstein, L. Comparative epidemiological study of attitudes to eating between students in China and Japan. Melbourne, AU: Asian Pacific Eating Disorder Congress; 2002.

National Eating Disorders Association. Web-based statistics and reporting system. 2006 [Retrieved September 20, 2007]. from http://www.edap.org/p.asp?WebPage_ID $=286 \&$ Profile_ID $=41138$

Nesse, RM. Evolutionary psychology and mental health. In: Buss, DM., editor. Handbook of Evolutionary Psychology. Hoboken, NJ: Wiley; 2005. p. 903-927.

Nesse, RM.; Williams, GC. Why we get sick : The new science of Darwinian medicine. New York: Times Books; 1994.

Neumark-Sztainer, D. I'm, Like, SO Fat!. New York: The Guilford Press; 2005.

Polivy, J.; Garner, DM.; Garfinkel, PE. Causes and consequences of the current preference for thin female physiques. In: Herman, CP.; Zanna, M.; Huggins, ET., editors. Physical Appearance, Stigma, and Social Behavior. Hillsdale, N J: Erlbaum; 1986. p. 89-112.

Rosen J, Jones A, Ramirez E, Waxman S. Body Shape Questionnaire: Studies of validity and reliability. International Journal of Eating Disorders 1996;20:315-319. [PubMed: 8912044]

Salmon C, Crawford C, Dane L, Zuberbier O. Ancestral mechanisms in modern environments: Impact of competition and stressors on body image and dieting behavior. Human Nature 2008;19:103-117.

Singh D. Adaptive significance of female physical attractiveness: Role of waist-to-hip ratio. Journal of Personality \& Social Psychology 1993;65:293-307. [PubMed: 8366421]

Smolak, L. National Eating Disorders Association/next door neighbors puppet guide book. Seattle, WA: National Eating Disorders Association; 1996.

Sobal I, Stunkard AJ. Socioeconomic status and obesity: A review of the literature. Psychological Bulletin 1989;05:260-275. [PubMed: 2648443]

Stiegel-Moore RH, Tucker N, Hsu J. Body image dissatisfaction and disordered eating in lesbian college students. International Journal of Eating Disorders 1990;9:493-500.

Surbey MK. Anorexia nervosa, amenorrhea, and adaptation. Ethology and Sociobiology 1987;8:47-61.

Symons, D. The evolution of human sexuality. New York: Oxford University Press; 1979.

Thompson, JK.; Heinberg, LJ.; Altabe, MN.; Tantleff-Dunn, S. Exacting beauty: Theory, assessment and treatment of body image disturbance. Washington, D.C.: American Psychological Association; 1999.

Tiggemann M, Slater A. Thin ideals in music television: A source of social comparison and body dissatisfaction. International Journal of Eating Disorders 2004;35:48-58. [PubMed: 14705157]

Vohs KD, Heatherton TF, Herrin M. Disordered eating and the transition to college: A prospective study. International Journal of Eating Disorders 2001;29:280-288. [PubMed: 11262506]

Voland E, Voland R. Evolutionary biology and psychiatry: The case of anorexia nervosa. Ethology and Sociobiology 1989;10:223-240.

Walters S, Crawford CB. The importance of mate attraction for intrasexual competition in men and women. Ethology and Sociobiology 1994;15:5-30. 
Wasser SK, Barash DP. Reproductive Suppression Among Female Mammals: Implications for Biomedicine and Sexual Selection Theory. The Quarterly Review of Biology 1983;58:513-538. [PubMed: 6686686]

Woodside, DB.; Kennedy, SH. Gender differences in eating disorders. In: Seeman, MV., editor. Gender and psychopathology. 1995. p. 253-268.

Yager J, Kurtzman F, Landsverk J, Weismeier E. Behaviors and attitudes related to eating disorders in homosexual male college students. American Journal of Psychiatry 1988;145:495-497. [PubMed: 3162355] 
Men

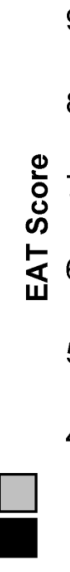

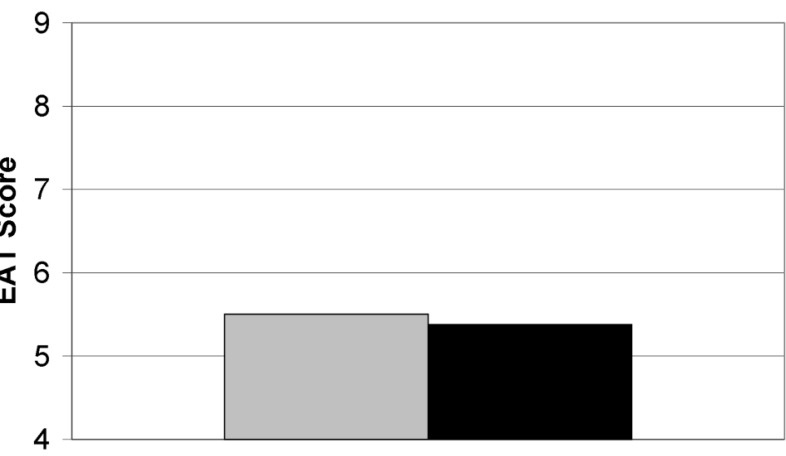

low status/noncompetitive

high status/competitive
Women

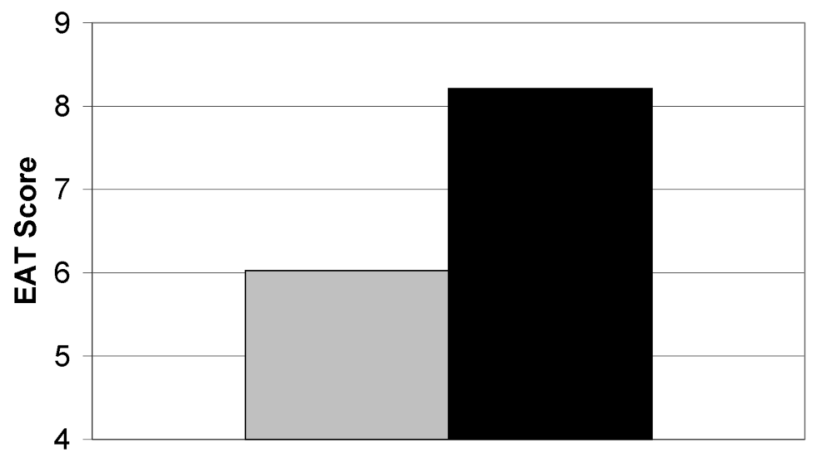

Fig. 1.

Influence of Intrasexual Competition Motives on Eating Restriction. 
Heterosexual Men

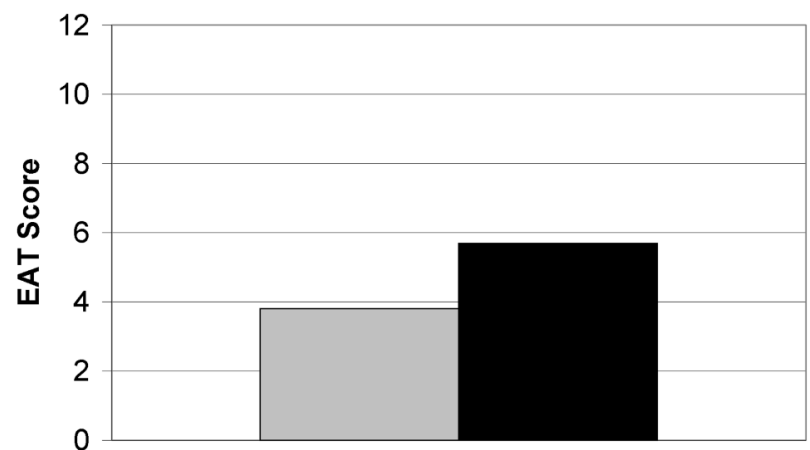

Heterosexual Women

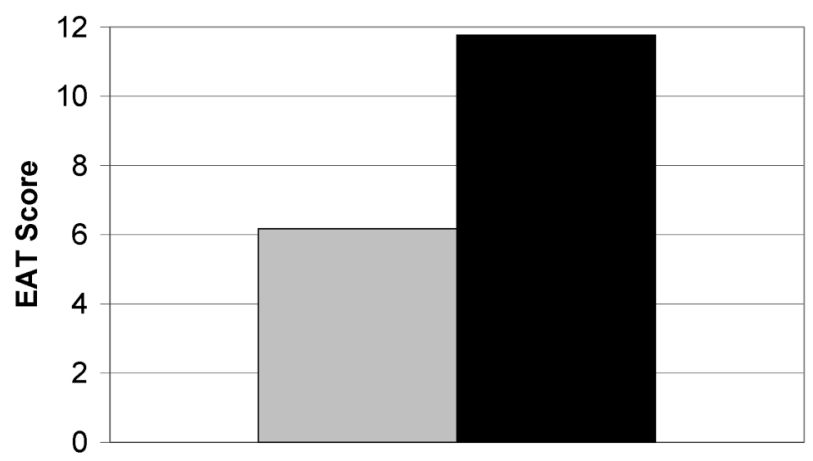

low status/noncompetitive

high status/competitive

Fig. 2.

Influence of Intrasexual Competition Motives on Eating Restriction in Heterosexual Individuals. 
Gay Men

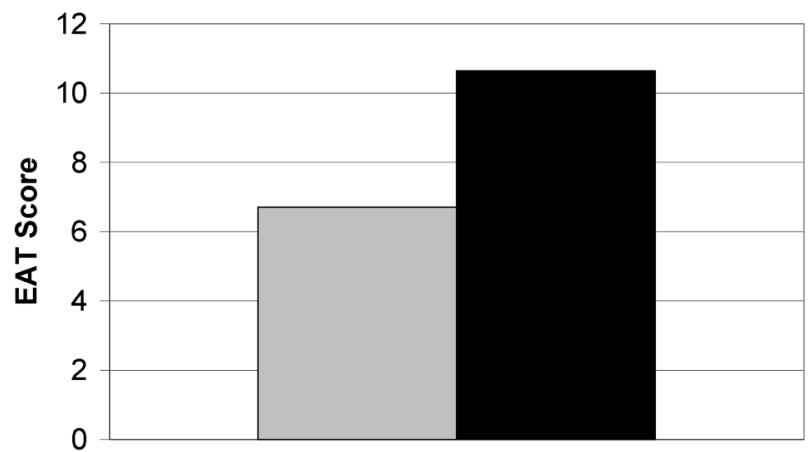

Lesbian Women

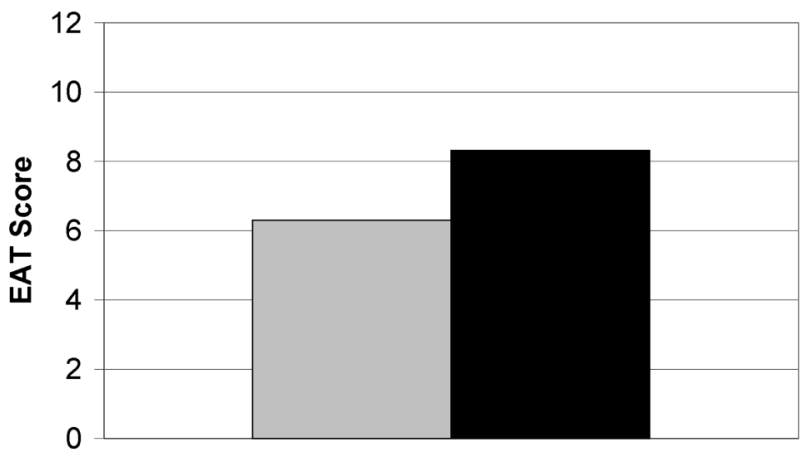

low status/noncompetitive high status/competitive

Fig. 3.

Influence of Intrasexual Competition Motives on Eating Restriction in Homosexual Individuals. 